\title{
Semi-quantitative analysis of solid waste flows from nano-enabled consumer products in Europe, Denmark and the United Kingdom - Abundance, distribution and management
}

Heggelund, Laura Roverskov; Hansen, Steffen Foss; Astrup, Thomas Fruergaard; Boldrin, Alessio

Published in:

Waste Management

Link to article, DOI:

10.1016/j.wasman.2016.05.030

Publication date:

2016

Document Version

Peer reviewed version

Link back to DTU Orbit

Citation (APA):

Heggelund, L. R., Hansen, S. F., Astrup, T. F., \& Boldrin, A. (2016). Semi-quantitative analysis of solid waste flows from nano-enabled consumer products in Europe, Denmark and the United Kingdom - Abundance, distribution and management. Waste Management, 56, 584-592. https://doi.org/10.1016/j.wasman.2016.05.030

\section{General rights}

Copyright and moral rights for the publications made accessible in the public portal are retained by the authors and/or other copyright owners and it is a condition of accessing publications that users recognise and abide by the legal requirements associated with these rights.

- Users may download and print one copy of any publication from the public portal for the purpose of private study or research.

- You may not further distribute the material or use it for any profit-making activity or commercial gain

- You may freely distribute the URL identifying the publication in the public portal 


\title{
Semi-quantitative analysis of solid waste flows from nano- enabled consumer products in Europe, Denmark and the United Kingdom - abundance, distribution and management
}

\author{
Laura Heggelund ${ }^{1,}{ }^{*}$, Steffen Foss Hansen ${ }^{1}$, Thomas Fruergaard Astrup ${ }^{1}$, Alessio Boldrin ${ }^{1}$ \\ 1) Department of Environmental Engineering, Technical University of Denmark, Miljoevej, Building 115, \\ Kgs. Lyngby, DK-2800, Denmark \\ *) Corresponding author
}

"NOTE: this is the author's version of a work that was accepted for publication in Waste Management journal. Changes resulting from the publishing process, such as peer review, editing, corrections, structural formatting, and other quality control mechanisms may not be reflected in this document. Minor changes may have been made to this manuscript since it was accepted for publication.

A definitive version is published in Waste Management 56, 584-592, doi: http://dx.doi.org/10.1016/j.wasman.2016.05.030" 


\begin{abstract}
Many nano-enabled consumer products are known to be in the global market. At the same, little is known about the quantity, type, location etc. of the engineered nanomaterials (ENMs) inside the products. This limits the scientific investigations of potential environmental effects of these materials, and especially the knowledge of ENM behaviour and potential effects at the end-of-life stage of the products is scarce. To gain a better understanding of the end-of-life waste treatment of nano-enabled consumer product, we provide an overview of the ENMs flowing into and throughout waste systems in Europe, Denmark and the United Kingdom. Using a nanoproduct inventory (nanodb.dk), we performed a four-step analysis to estimate the most abundant ENMs and in which waste fractions they are present. We found that in terms of number of products: (i) nano silver is the most used ENM in consumer products, and (ii) plastic from used product containers is the largest waste fraction also comprising a large variety of ENMs, though possibly in very small masses. Also, we showed that the local waste management system can influence the distribution of ENMs. It is recommended that future research focus on recycling and landfilling of nano-enabled products since these compartments represent hot spots for end-of-life nanoproducts.
\end{abstract}

Abbreviations: Engineered nanomaterials (ENMs), engineered nanomaterial (ENM) 


\section{Introduction}

The global market for nano-enabled consumer products is expanding steadily (Hansen et al. 2016). Consequently, increasing amounts of consumer waste containing engineered nanomaterials (ENMs) are being generated which will eventually find their way into various forms of waste treatment processes (incineration, waste water treatment plants, etc.) not originally designed to treat such materials (OECD 2016). As previously discussed in the literature (e.g. Nowack et al. 2012, Part et al. 2015) the emergence of nanoproducts raises a number of important issues when it comes to these products' end-of-life (EOL), waste treatment and waste handling, as very little is known about: i) the potential transformations of nanoproducts and nanomaterials during different waste treatments, ii) the interactions between ENMs and other constituents of waste, iii) the magnitude of ENMs released into the environment after waste treatment and iv) the potential transformations/effects of modified ENMs in the environment.

Some experimental studies have investigated the fate and behaviour of nanomaterials in simulated landfill conditions (e.g. Bolyard et al. 2013, Lozano \& Berge 2012) and their results indicate that organic matter influences the stability and mobility of ENMs. However, these studies look at the behaviour of pristine ENMs which are usually not expected to enter the environment (Nowack et al. 2012). Another way to approach these concerns is to gain a basic understanding of ENMs flowing into and throughout waste systems, addressing, for instance, which types of nanoproducts are expected to enter current waste management systems, as well as which kinds are potentially the most abundant and in what form they reach waste treatment facilities.

Different modelling approaches have been used to address some of the abovementioned aspects, including material flow modelling (Gottschalk et al. 2009, Walser \& Gottschalk 2014, Sun et al. 2014), market analysis (Keller \& Lazareva 2014, Keller et al. 2014, Boldrin et al. 2014), life cycle assessment (Pourzahedi \& Eckelman 2015, Hischier et al. 2015) and modelling by categorisation, based on consumer product inventories (Asmatulu et al. 2012).

Probabilistic material flow models have been used to predict concentrations of ENMs in the environment (Gottschalk et al. 2009, Walser \& Gottschalk 2014, Sun et al. 2014) and in recycling processes (CaballeroGuzman et al. 2014). These studies use probabilistic distribution curves as input data instead of the generally uncertain and inadequate datasets available on engineered nanomaterial (ENM) fate and behaviour in the environment.

Recently, Sun et al. (2014) modelled the concentrations of selected ENMs (nano-TiO 2 , nano-Ag, nano-ZnO, fullerenes and CNTs) in environmental and technical compartments and compared these with non-nano metal-based counterparts $\left(\mathrm{TiO}_{2}, \mathrm{Ag}, \mathrm{ZnO}\right)$. Technical compartments refer to sewage treatment plants, waste incineration plants, landfills and recycling stations as well as the "emissions" related to these, such as sewage sludge and bottom ash. Compared to the environmental compartments (air, soil, sediment and water), the highest modelled concentrations were estimated for the technical compartments. Among these, the highest concentrations are expected to occur in sewage sludge, followed by solid waste and waste incineration ashes (fly and bottom ash). The technical compartments presented concentrations in the $\mathrm{mg} / \mathrm{kg}$ range, whereas the environmental compartments only showed them in the $\mathrm{ng}-\mu \mathrm{g} / \mathrm{kg}$ range, though it should be mentioned that these values represent modelled yearly increases in each compartment. These findings support the relevance of further studies on ENM quantification and characterisation in waste treatment compartments since they constitute a likely sink for ENMs.

The modelling approaches have a mayor limitation namely that the analytical techniques currently available are not able to detect ENMs in complex matrices. This means that the models cannot be validated with actual measurement of ENMs released into the environment or during waste treatment (Part et al. 2015, Nowack et al. 2015). The challenges of detecting ENMs in waste streams have recently been reviewed by Part et al. (2015). In this review, promising techniques for nanomaterial quantification, such as separation techniques combined with spectrometry-based methods and imaging, are discussed. However, the authors also highlight the fact that currently these analytical techniques are not able to distinguish between engineered and naturally occurring nanomaterials. 
In general, the abundance of nanoproducts, the type of nanoproducts, the nanomaterial used, the form of the nanomaterial and the product matrix, as well as waste handling and treatment processes, will have a profound impact on the EOL of the ENMs.

The aim of this paper is to provide a systematic and consistent basis for prioritising efforts related to handling ENMs within the waste management system. This is achieved by: i) developing tools for the analysis of nanoproducts in solid waste flows, ii) assessing the relative importance of ENMs and waste types, iii) identifying critical aspects with respect to specific ENMs and waste treatment combinations and iv) establishing waste scenarios (for the EU, Denmark and the UK) to identify the waste treatment options involved in this regard.

\section{Methodology}

The method for conducting the analysis of waste flows is divided into four steps:

1. Categorisation of available nano-enabled products into waste material fractions

2. Estimation of the types of ENMs present in waste material fractions

3. Estimation of the region-specific waste management of individual waste material fractions

4. Combination of steps 2 and 3, to determine the distribution of ENMs routed to specific waste treatment options.

The four steps are explained in detail in the following sections.

\subsection{Step 1: Categorisation of products available on the Nanodatabase}

The first step in the process towards mapping the abundance, distribution and waste treatment of nanoproducts is to assign individual nanoproducts to waste material fractions. To do this, we used The Nanodatabase (nanodb.dk), an online inventory of products known to be available to European consumers either via retailers or via online shops. The database was established by DTU and others in 2012 and currently contains 2312 products (8/4-2016, nanodb.dk). Information about each product is collected based on data that producers provide publicly online, such as the type of ENM or a description of the product. A more thorough description of how products are included in the database is given in the recent paper by Hansen et al. (2016).

Based on the information available on The Nanodatabase, we identified the main matrix material of each individual product and its corresponding waste material fraction, e.g. a product in a plastic container falls into the waste fraction named "Plastic packaging". Categorisation is based on an image of the product, along with any other information made available by the manufacturer online. In some cases, we created specific fractions which were adapted to products on the database, e.g. "Plastic, other." These products made from plastic, e.g. hockey sticks, food containers or baby bottles, are separated from plastic packaging waste, since the ENMs in these plastic products, contrary to the case of plastic packaging, are usually embedded in the plastic or are coated on the surface, and they are considered potentially more suitable for recycling. Hence, they might also be handled differently in the waste management system. On occasion it was not possible to create a homogenous fraction, for example when a product consisted of more than one main material which could not readily be separated (e.g. camera lenses, a baby carriage and a water filtering unit). These products were grouped into a "Multi-material waste" fraction, comprising products of many sizes and applications. Other products in The Nanodatabase in reality consists of multiple individual products, e.g. an automotive cleaning kit including products in both plastic and metal containers, and in these cases we adjusted the data before analysis, so each individual product in the kit was allocated to its own waste material fraction. This means that these products were copied and routed to several waste fractions, and therefore the number of products in our analysis varies slightly from what can be found in The Nanodatabase. Products were categorised as unknown if no image was available showing the specific product and the container it was sold in, or it couldn't be derived from the product description. 


\subsection{Step 2: Identification of the types of ENM present in the waste material fractions}

For each product in the Nanodatabase, the identity of ENMs claimed to be used in the product was noted, if reported by the manufacturer. In total the nanomaterial was reported for 970 products $(8 / 4-2016$, nanodb.dk). This information was used subsequently to identify ENM types in the waste material fractions, which in turn allowed for an assessment of the relative importance of the ENM types in each waste fraction. It has to be noted that for $40 \%$ of the products in the database, the identity of the ENM is not described by the manufacturer or others, and these products were therefore not included in our analysis of waste flows.

\subsection{Step 3: Identification of region-specific waste management of individual waste material fractions}

From Eurostat (http://ec.europa.eu/eurostat/web/waste) we collected the most recent data on the waste treatment of selected waste fractions and included four possible waste management options, defined as: incineration, recycling, landfilling and anaerobic digestion/composting. For this research we analysed three case studies: Europe (EU average), United Kingdom (UK) and Denmark (DK). We chose these regions because they are within the scope of the Nanodatabase and represent different waste management systems, i.e. an average for Europe, a system traditionally relying on landfilling (UK) and one making significant use of incineration and energy recovery (DK). Statistical data were used to route individual waste material fractions to their likely waste treatment option. The fractions created for the purpose of this analysis, and which had no appropriate waste treatment statistics available (i.e. "Plastic, other", "Multi-material waste" and "Unknown"), were routed to the waste treatment system based on average statistics for handling "Municipal solid waste (MSW)".

\subsection{Step 4: Combination of steps 2 and 3, to determine the distribution of ENM routed to specific waste management options}

Further analysis of the distribution of ENMs in the most common solid waste treatment technologies, i.e. incineration, recycling, landfilling and anaerobic digestion/composting, was performed by combining the waste material fractions (step 2) with waste treatment scenarios for a specific region (step 3). In so doing, we were able to identify important or critical combinations of nano-enabled products and potential waste management systems. In the present study, we report on ENM distribution in Denmark, United Kingdom and Europe, but the analysis can be adapted to the infrastructure of a specific region or country, as long as detailed data on the local waste management system are available.

\section{Results}

\subsection{ENM distribution in waste material fractions}

In total, we identified 9 different relevant waste material fractions (see Table 1). The waste fractions ceramics and wood were not included since only few products fall in these categories. The distribution of ENMs (or combinations thereof, such as silver and titanium) expected to be found in individual fractions is shown in Figure 1, according to the number of products assigned to respective waste fractions. We found that the most abundant ENM across all waste fractions is silver (see Figure 1), which is in line with the wide range of applications for nano silver in consumer products; for example, it is used in 20 different product subcategories corresponding to 340 products (nanodb.dk). In comparison, nano titanium dioxide is only used in 12 different product subcategories, although it is a quite abundant material used in 101 products (nanodb.dk). The largest waste fraction is "Plastic, packaging" (847 products) followed by "Textile" (390 products) and "Electronics" (306 products). Plastic packaging waste also comprises the largest variety of ENMs (20 different ENMs), which might be caused by the fact that this waste material fraction is generated by many different sources (product categories), such as the automotive, food \& beverage and home \& garden 
sectors. Minor waste material fractions include, for example, glass waste and batteries, which are primarily generated by the health $\&$ fitness sector and waste from appliances, respectively.

Table 1 - Description of waste material fractions in the Nanodatabase (nanodb.dk).

\begin{tabular}{|l|l|}
\hline Waste material fraction & \multicolumn{1}{|c|}{ Description and examples } \\
\hline Batteries & $\begin{array}{l}\text { Typically these products are batteries for an electrical item, where the nanocomponent is } \\
\text { only present in the battery. }\end{array}$ \\
\hline Electronics & Generally products with electric connections, e.g. refrigerators, hairdryers, electric toys, etc. \\
\hline Glass & Cosmetic products, supplements or other products sold in glass containers. \\
\hline Metal & Generally consists of containers such as cans, or metal sports equipment. \\
\hline Multi-material waste & $\begin{array}{l}\text { These products contain more than one material which cannot readily be separated, e.g. } \\
\text { camera lenses, a baby carriage and a water filtering unit. }\end{array}$ \\
\hline Plastic packaging & $\begin{array}{l}\text { Typically waste from used plastic containers for cleaning/cosmetic products, which have a } \\
\text { residue of the nanoproduct in them. }\end{array}$ \\
\hline Plastic, other & $\begin{array}{l}\text { Generally plastic products where the nano component is embedded in/surface coats the } \\
\text { plastic, such as sports equipment, baby bottles, food containers and toothbrushes. }\end{array}$ \\
\hline Textile & $\begin{array}{l}\text { Fibrous material, typically clothing or bandages, with a nano coating or nanomaterial } \\
\text { embedded in the fibres. }\end{array}$ \\
\hline Unknown & $\begin{array}{l}\text { If no image is available showing the specific product and the container it is sold in, or it } \\
\text { cannot be derived from the product description, this category is used. }\end{array}$ \\
\hline
\end{tabular}

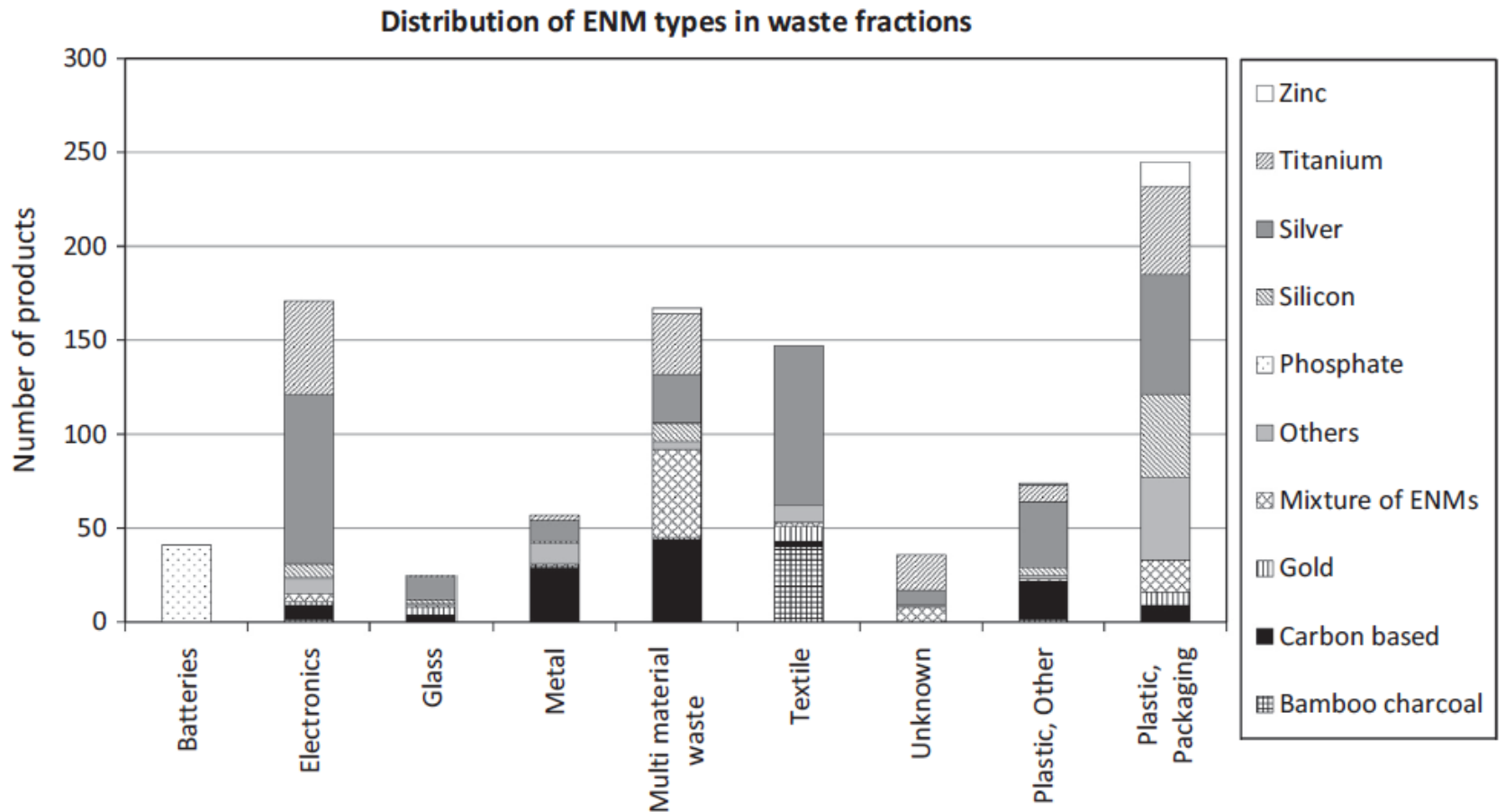

Figure 1 - Distribution of ENM in the different waste material fractions according to data from nanodb.dk. The Y-axis represents the number of products containing a certain ENM (nanodb.dk). Please note that the products have been grouped according to which primary nanotechnology substance they contain, e.g. "Titanium" includes both titanium and titanium dioxide, and "carbon based" includes CNTs, carbon black, fullerenes and graphite. 


\subsection{Collection of statistical data for waste management in the EU}

Table 2 shows how individual waste fractions are treated within the three regions of interest, i.e. Europe (EU), Denmark (DK) and the United Kingdom (UK). When comparing Table 1 and Table 2, minor differences are seen between the waste fractions, due to the customisation of some of them, i.e. "Plastic, other", "Multimaterial waste" and "Unknown".

Table 2 - Management of individual waste material fractions in the three analysed scenarios: Europe (EU), Denmark (DK) and the United Kingdom (UK) (Eurostat, http://ec.europa.eu/eurostat/web/waste). Please note that, for sake of simplicity, numbers are rounded and may hence not add up to $100 \%$.

\begin{tabular}{|l|c|c|c|c|c|c|c|c|c|c|c|c|}
\hline & \multicolumn{9}{|c|}{ Distribution to waste management options (\%) } \\
\hline & \multicolumn{3}{|c|}{ Incineration } & \multicolumn{3}{|c|}{ Landfilling } & \multicolumn{3}{c|}{$\begin{array}{c}\text { Recycling } \\
\text { Anaerobic } \\
\text { digestion/compost }\end{array}$} \\
\hline & EU & DK & UK & EU & DK & UK & EU & DK & UK & EU & DK & UK \\
\hline Batteries & 5 & 5 & 5 & 8 & 8 & 8 & 88 & 88 & 88 & & & \\
\hline Electronics & 6 & 11 & 4 & 9 & 1 & 10 & 85 & 89 & 86 & & & \\
\hline Glass & 12 & 2 & 10 & 16 & 0 & 22 & 73 & 98 & 68 & & & \\
\hline Metal & 12 & 46 & 15 & 16 & 2 & 33 & 73 & 52 & 52 & & & \\
\hline Plastic, packaging & 27 & 67 & 23 & 37 & 3 & 51 & 35 & 29 & 25 & & & \\
\hline $\begin{array}{l}\text { Average municipal solid waste } \\
\text { (MSW) }\end{array}$ & 24 & 52 & 17 & 34 & 3 & 37 & 27 & 32 & 28 & 15 & 13 & 18 \\
\hline Textile & 17 & 3 & 5 & 26 & 39 & 2 & 56 & 58 & 93 & & & \\
\hline
\end{tabular}

By combining information from Figure 1 and Table 2, we estimated the relative distribution of nanoproducts to waste treatment technologies (Figure 2). For all three regions we found that, within the waste fractions we identified, more than $50 \%$ of the nanoproducts are likely to end up in recycling processes. However, this will not be the final destination for the ENM in these products, because the ENM is not expected to be associated with recyclable fractions of the products, which are routed back to production and manufacturing industries (Caballero-Guzman et al., 2015). Significant differences appear when looking at the incineration and landfilling treatment options. Europe and the UK are quite comparable, routing $19 \%$ and $13 \%$ to incineration and $26 \%$ and $29 \%$ to landfilling, respectively (Figure 2). Conversely, Denmark, to a large extent, makes use of incineration with energy recovery, resulting in $38 \%$ of nanoproducts ending up in waste incineration plants and only $8 \%$ in landfills (Figure 2 ).

\subsection{ENM distribution to incineration, landfill, recycling and compost/anaerobic digestion}

When we combined data from step 2, where we investigated ENM distribution in various waste fractions, and step 3, where we collected statistical data for the waste management of these fractions in the EU, the UK and Denmark, we were able to assess to what extent individual ENMs would enter specific waste treatment technologies (i.e. incineration, recycling, landfilling and anaerobic digestion), as shown in Figure 3. For example, $31 \%$ of EOL nano-enabled consumer products in Europe entering a waste incineration plant will contain nano silver (see Figure 3). Generally, anaerobic digestion/compost is not a very relevant waste treatment scenario in terms of solid streams of nano-enabled consumer products, according to this analysis. This is reflected in figure 3 where the small size of the pie charts indicate that few nanoproducts are likely to be routed this way. 


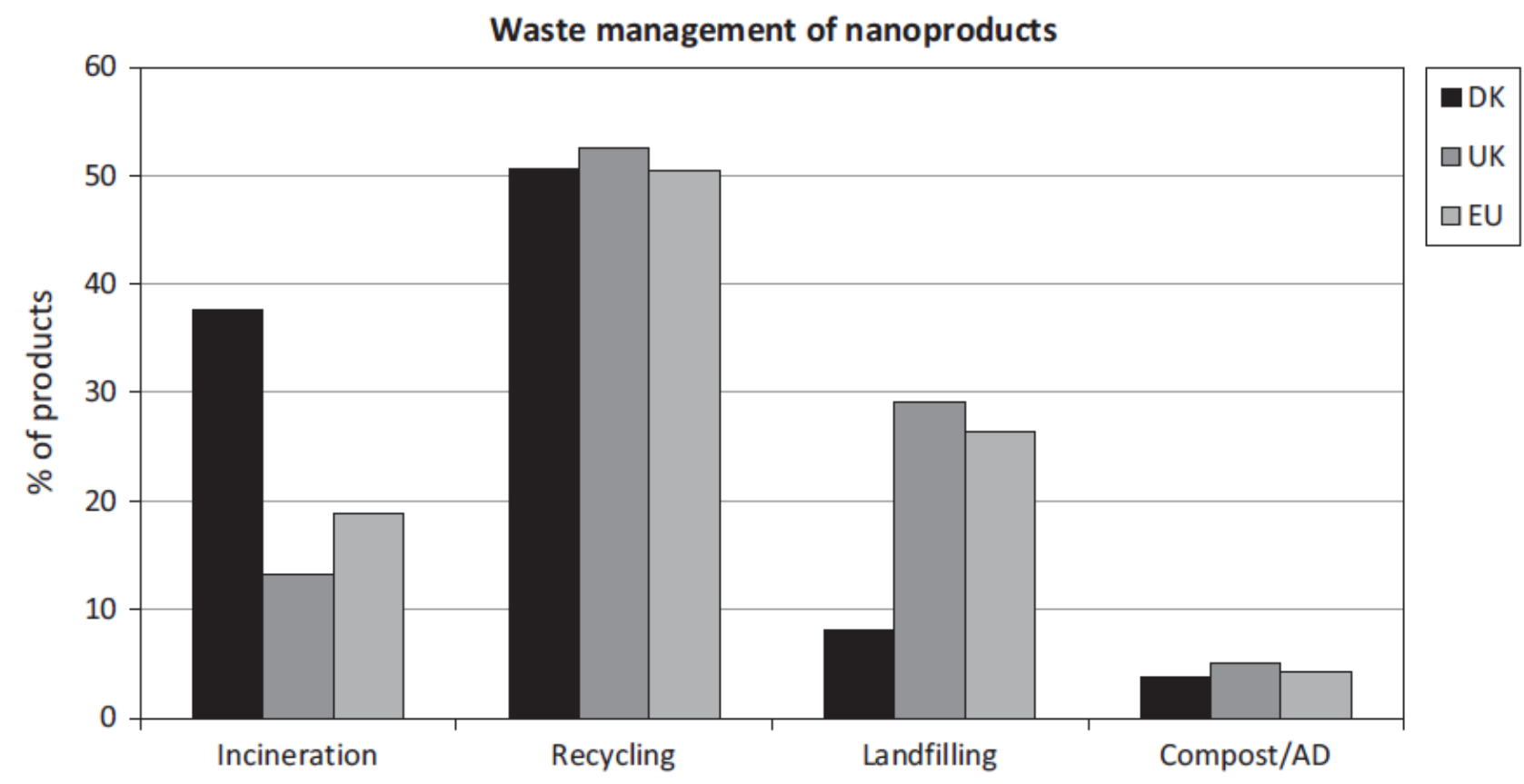

Figure 2 - Relative distribution (\%) of end-of-life nanoproducts into waste treatment options in the three analysed scenarios: Europe (EU), Denmark (DK) and the United Kingdom (UK).

As expected, we found that nano silver is widespread and represents the largest fraction of ENM in all management scenarios and regions (Figure 3). The distribution of ENMs in the different waste management systems is generally similar for Europe, e.g. the number of items containing silver and titanium ENM is more or less the same, regardless of the management scenario. However, if we compare incineration and recycling in Europe, is it clear that there is a higher percentage of phosphate ENM in the recycling scenarios, as a result of the large amount of batteries being recycled.

Based on our analysis of ENM distribution in Danish and UK solid waste (see Figure 3), we observe some differences as a consequence of the local waste system. For example, as Denmark relies principally on waste incineration and only makes use of landfilling to a small degree, many more products end up in landfills in the UK (280 products,) compared to Denmark (78 products). The significant differences between Denmark and the UK occur specifically in the treatment of plastic packaging and textile waste (see Table 2). Because greater amounts of plastic waste (both packaging and other plastic) are disposed of in landfills in the UK, the proportions of titanium- and carbon-based ENMs are higher in the UK landfill scenario. On the other hand, Danish landfills, according to the data, receive larger amounts of textile waste which typically contains bamboo charcoal and nano gold. Furthermore, batteries containing nano phosphate are more prevalent in Danish landfills. However, it should be mentioned that there is some discrepancy between the data we obtained from Eurostat, and the actual management of textile waste. In fact, it is not permissible to landfill textile waste in Denmark, which illustrates the importance of obtaining as accurate local waste management statistics as possible. 


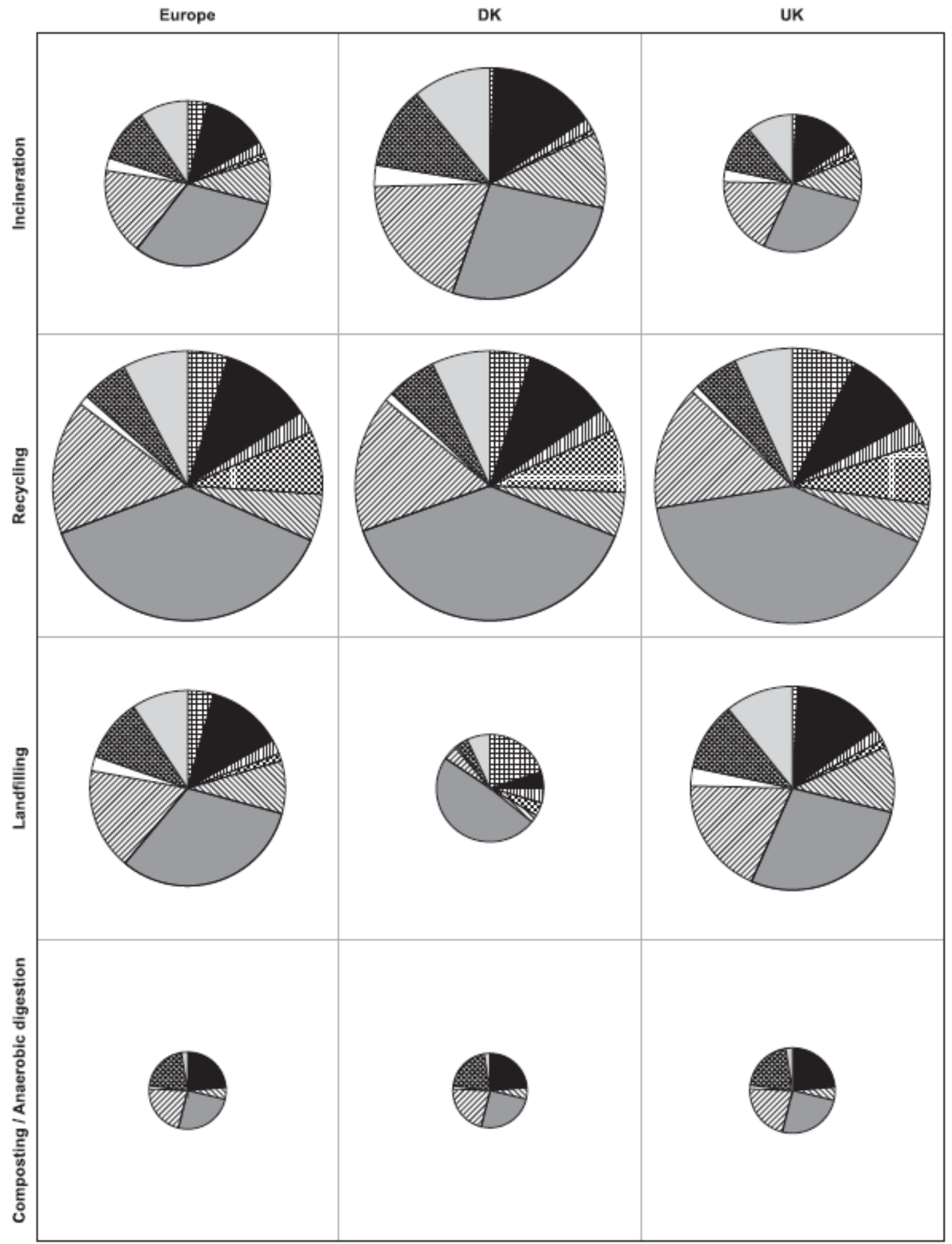

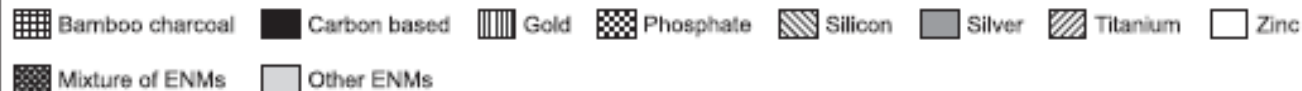

Figure 3 - Distribution of nanomaterials for the four different waste management options: incineration, recycling, landfilling and composting/anaerobic digestion. The figure illustrates the percentage of products entering a waste treatment option that will contain a certain ENM. Note: the area of the pie is proportional to the number of products entering individual treatments, thus reflecting the size of the bars in Fig. 2. 


\section{Discussion}

In this study, we performed a four-step analysis of nanoproducts available in the European market, to identify their fate in waste management systems. To perform the analysis, we used the Nanodatabase online product inventory, which comprises a continuously updated database of nanoproducts available to European consumers. We did this in order to provide an overview of the relative importance of specific ENMs and waste treatment options, and to identify potentially critical combinations thereof.

We found that nano silver is ubiquitous in all of the waste streams investigated. Furthermore, recycling is identified as the compartment receiving the most nanoproducts - and thereby also a large variety of ENMs.

In a previous study, Hansen et al. (2015) found that nano silver was the most abundant ENM in consumer products, in terms of number of products available. Our analysis of the product inventory also highlighted that some waste material fractions are more homogenous than others when it comes to the number of different ENMs expected to be present. The most homogenous fraction is batteries, whereas plastic packaging and electronic waste are some of the most heterogeneous. This pattern was also identified by Struwe \& Schindler (2012). In the evaluation of potential occupational risks during recycling, Struwe \& Schindler (2012) distinguished between two types of waste containing nanomaterials: i) waste with a heterogeneous composition consisting of a variety of products and ENMs, e.g. WEEE and most plastic waste (specific ENMs are often not known), and ii) waste with a more homogeneous composition and containing few ENMs, which are often known, e.g. PET bottles and Li-ion batteries.

It has to be stressed that our analysis is based on the number of products appearing in a certain category or fraction on the Nanodatabase. The analysis provides no information regarding mass or volume of these materials. Furthermore, many products on the Nanodatabase contain an unknown ENM, and hence they could not be included in this analysis. Another source of uncertainty lies in the categorisation of products, some of which are easily placed in a waste material fraction, e.g. electronics, textiles and metal, whereas others are not, e.g. multi-material waste and glass.

\subsection{Comparison with other modelling studies}

While adopting a different approach, our findings are in line with other studies that have modelled the flow of ENM from production, manufacturing and consumption into technical and natural compartments (Gottschalk et al. 2009, Sun et al. 2014, Keller et al. 2013). In their recent study, for instance, Sun et al. (2014) modelled the flow of selected ENMs based on yearly production volumes. The results for nano titanium dioxide, silver and zinc oxide are in line with ours, since they also identify recycling as a significant compartment for these ENMs. However, in their case, the importance of the compartment varies with the specific ENM in question. For example, the amount of material containing nano titanium dioxide going to recycling corresponds to approximately $18 \%$ of total waste production, whereas for nano silver the proportion is approximately $37 \%$ (Sun et al. 2014). Overall, for the metal-based ENMs investigated in the study by Sun et al. (2014), sewage treatment - and primarily sewage sludge - is expected to be the main EOL compartment, meaning that these ENMs will most likely be incinerated or applied to land. However, as also highlighted in this study, the final concentrations of ENMs cannot be verified currently, due to analytical constraints which do not allow for the distinction between engineered and naturally occurring nanomaterials in the environment. Additionally, environmental concentrations are very dependent on production volumes, and the conventional counterparts to ENMs are produced in far larger amounts, meaning that their environmental concentrations are expected to be one to seven orders of magnitude higher than for ENMs (Sun et al. 2014).

Another study, by Keller et al. (2013), was a first attempt to model the global environmental release of ENMs. The study combined ENM market information and material flow modeling to assess the emissions of large production volume ENMs (e.g. silica, titanium and alumina) into the environment and landfills. In the study, it was estimated that $63-91 \%$ of the global ENM production in 2010 ended up in landfills. Waste 
incineration and waste water treatment were considered intermediate compartments since the authors assume that all slag and filters from waste incineration will be landfilled along with the sludge from sewage treatment plants, unless it is applied to land. Recycling of nanoproducts is not considered in this analysis, which makes it difficult to compare with our results. The study by Keller et al. (2013) assessed the global production and disposal of ENMs by dividing the world into eight regions and extrapolating the available data for waste generation and disposal. This is different from our approach, since we tried to illustrate the impact of local waste management systems on the distribution of ENMs.

The Danish EPA recently published a report on nanomaterials in waste (Andersen et al., 2015), in which seven common combinations of waste category and ENM type are proposed, e.g. textile waste containing: nano silver, CNTs, nano silicon dioxide and nano titanium dioxide. Out of the seven categories, four to five are relevant to the focus of our study, since they mainly represent waste from consumer products. Andersen et al. (2015) reported that CNTs and nano silver were commonplace in metal waste, which is in good agreement with our results. This also applies to the textile waste fraction, where CNTs, nano silver and nano titanium dioxide are present in both studies. Contrary to the Danish EPA report, we do not find nano silica dioxide in either metal or textile waste. This could indicate that the Nanodatabase does not include these silica-containing products, due to lack of claims about "nano" properties, or that there is a difference in how manufacturers name their materials, which could cause some discrepancy.

In our analysis, the recycling management option receives many products and nanomaterials. A good number of different recycling processes can take place according to which waste material is considered. The Danish EPA has identified the following processes as being relevant to the release of ENMs during recycling: collection and sorting, shredding, pulping and re-granulation (Andersen et al., 2015). Many of these processes are expected to release ENMs associated with dust particles, meaning that workers involved in the recycling industry may be exposed to inhalable ENMs. According to our analysis, the waste fractions "Plastic, other" and "Electronics" will be recycled to a high extent, which could thus raise concerns about occupational safety during recycling, since these fractions also contain a large variety of ENMs. Further investigation into the issue is therefore advisable.

When discussing recycling as the final EOL management of waste containing ENMs, it has to be noted that only a small amount of a specific ENM is estimated to be channelled back into the production chain (Andersen et al., 2015). Andersen et al. (2015) modelled the recycling flows in Denmark for products containing nano titanium dioxide, nano zinc oxide, nano silver and CNTs, and found that after sorting and other recycling processes had taken place, most of the ENM would end up in an incineration plant or a landfill, or it would be exported. In the report, it was estimated that only $2 \%, 5 \%, 0.2 \%$ and $1.5 \%$ of nano titanium dioxide, nano zinc oxide, nano silver and CNTs, respectively, would be fed back into the production chain (Andersen et al., 2015). One explanation was that the ENM was not present in the recyclable fraction of a particular product. This information infers that even though our analysis shows that significant emphasis should be placed on the recycling of nano-enabled products, most of the ENM will eventually reach other EOL waste treatments.

Some studies have been performed on CNTs in plastic matrices. Since CNTs are used widely in plastic products, packaging and casings for electronics, plastic waste potentially also contains considerable amounts of CNTs. Our analysis shows that plastic waste is managed differently across Europe, and in a region such as the UK it may be landfilled to a high extent. Under the right circumstances, i.e. low pH in the landfill, this could lead to the release of CNTs, since the plastic matrix of battery casings, for instance, can be corroded (Köhler et al. 2008). This gives rise to concerns surrounding the low degradability of CNTs in the environment. According to Nowack et al. (2013), the release of CNTs in a landfill is expected to be very slow, but even though the total mass in this instance is small, the slow release and high persistency combined with significant toxicity demonstrate the need for long-term testing under environmentally relevant conditions. Other ENMs, such as nano zinc oxide and nano titanium dioxide, have been shown to be stable in mature landfill leachate over a 60-day time period (Bolyard et al. 2013). These EMNs are widely used in consumer products, and in our analysis they are both shown to distribute to landfills after disposal. This again lends support to the argument for the long-term testing of ENMs under landfill conditions. 


\subsection{Unknown ENMs used in products on the European market}

One of the major limitations with regards to our work, and the research on nanowaste in general, relates to the great lack of information on the specific ENM types used in many products available to consumers. This is reflected in the Nanodatabase, where $40 \%$ of products contain a nanomaterial whose identity has not been reported and therefore remains unknown. This illustrates the confusion and general lack of regulation regarding the labelling of nanomaterials in most nano-enabled consumer products, and it also poses a major problem for our analysis. Cosmetics legislation and the biocides regulation in Europe requires that ingredients in nano form have to have "nano" written in brackets after the name of the ingredient, for example "Titanium dioxide [nano]," but these uses of nanomaterials are exceptions. In the analysis carried out in our study, we chose to exclude products for which the identity of the nanomaterial is unknown, which significantly decreased the number of items we could subject to our analysis.

\subsection{Categorisation of products into waste material fractions}

In the initial step of the analysis many considerations were made regarding the choice of material fractions and their homogeneity. One challenge in this respect is the handling of the custom-made waste material fractions /categories such as "Multi-material waste" and "Plastic, other". We used statistics for the management of MSW, to enable the analysis of these products. However, as explained previously, these fractions are quite heterogeneous, and to manage them as MSW might be a valid approximation for some but surely not for all products.

Another challenge is the fact that, for some products, the waste material fraction is difficult to identify, which in turn introduces some uncertainly into the analysis.

When we assigned individual products on the database to a specific waste fraction based on the main matrix material - as opposed to dealing with general product categories and their likely disposal - there was a risk of misplacing products, and some carried a higher uncertainly because they are complex and consist of different kinds of materials. This should be taken into account when interpreting the results of the present analysis. Complex products are often assigned to a waste fraction created for the purpose of analysing this product inventory (e.g. multi-material waste), even though they can be very different, e.g. sports equipment, baby trolleys and camera lenses. This may create a problem when routing them to the waste treatment options.

Finally, as some manufacturers do not provide information on the ENM in their product and do not provide a suitable photo and/or description of the product container/packaging, we were forced to place these items in the waste material fraction "Unknown".

\subsection{Number-based analysis and waste management statistics}

In our analysis, we did not consider at any stage the mass of ENM; instead, we based our analysis on the number of products. While allowing for a comprehensive analysis of many products, the results of such an approach should be evaluated with care, in order to avoid misinterpretations. For instance, we conclude that nano silver is widespread across all waste fractions. However, one has to bear in mind that nano silver is produced in very small amounts compared to, for instance, nano titanium oxide (European Commission, 2012). According to a report from the French nano registry, nano silver was produced, imported or distributed in amounts ranging from 0,1-1 kg in 2015 in France (Ministére de l'Environnement, de l'Enegie et de la Mar 2015). There seems to be a discrepancy between the amount of products containing nano silver and the amounts of nano silver actually being produced. This could be due to the fact that the data from the French registry may not take into account the increase in the number of nanoproducts that we have seen since 2012 (Hansen et al. 2016) since many of the products available in Europe are not produced in Europe, but are imported.. 
Another issue with our number-based analysis lies in the material fraction "Plastic packaging". This fraction displays the largest number of products, but it might contain less significant amounts of ENM based on mass, since only a residual portion of the product containing the ENM remains in the container by the time of disposal.

While performing the analysis, we also encountered a different problem concerning the chosen statistical waste management data. First of all, the data we obtained from Eurostat were not detailed enough to describe exactly the waste fractions that we identified, since we were dealing specifically with nano-enabled consumer products. Also, we found that the Eurostat database provided possibly inconsistent data in some cases, an example being statistics regarding the management of textile waste in Denmark, which does not correspond with actual Danish practice. It might be a more useful approximation, therefore, to utilise local waste management data, if they are accessible, and combine these with local expert judgements and estimates when statistics are incomplete. However, this approach compromises comparability across countries or regions, which was also the aim of this study.

\section{Recommendations and perspectives}

Our study provides a preliminary analysis of ENM distribution in waste management systems. It points to a general need for an increased research effort when it comes to the recycling and landfilling of nano-enabled products. This research can help prioritise future research work on the most relevant EOL scenarios and possibly encourage a move away from the least relevant. For instance, it might not be relevance to test nano zinc oxide in glass waste under landfill conditions, as our analysis shows that nano zinc oxide is not widely used in glass (at least for consumer products), and landfilling of glass is not a common practice in the EU (16\% of the material).

On the other hand, we found that nano silver is widespread across waste fractions and waste treatment options, which implies that there is a need for a broad research strategy concerning EOL consumer products containing nano silver, since it may undergo a large variety of treatments - ultimately affecting the environmental fate of the ENM.

In terms of numbers of products, recycling is still the most important category, and so increasing focus should be put on the possible transformations and risks concerning nano silver in recycling systems. Only one study was found (Caballero-Guzman et al., 2015) which looks specifically at the recycling of ENMs in different product categories. However, as mentioned only some of the material fractions will be suitable for recycling, and the ENMs are usually not present in these recyclable fractions of the product. Therefore, the authors conclude that only a small part of the ENMs in recycled products will end up going back into the production and manufacturing chain. Instead, the non-recyclable fractions (containing the ENMs) will most likely be either incinerated or landfilled, which underlines the fact that recycling should not be seen as the final destination for these ENMs.

Another apparent need, in order to improve the understanding and modelling of ENMs in waste management systems, is data generation, e.g. the fate and behaviour of ENM in simulated waste treatment scenarios such as landfill leachate solution, or the pilot-scale incineration of ENM containing products/materials. This could be achieved by performing standard waste characterisation tests on nanocontaining matrices and evaluating the potential release of ENM. In this way, we would also meet the need for evaluating the applicability of standard waste characterisation methods to nano-enabled materials, and possibly highlight safe-by-design features concerning EOL nanoproducts.

The Nanodatabase played a pivotal role in our analysis, and, in order for our analysis to continue to be relevant, we plan to update it continuously, both in terms of new products entering the market and products taken off the market. The usefulness of our work would, however, will be significantly improved if the mass or volume of ENM, as well as of product items marketed and sold, was made available in the open literature and could be integrated in the analysis. However, this requires a significant amount of data from industry, 
which is unlikely to be attainable unless regulation is put in place that makes this information publicly available.

\section{Conclusions}

Our analysis shows that nano silver is widespread across waste fractions and waste treatments, by considering the number of nano-enabled products available in the current market. Plastic packaging is the largest waste fraction in terms of product numbers, and it comprises a large variety of ENMs. However, this waste fraction is also expected to contain small amounts of ENMs based on mass, since only a residue of the product is expected to be left by the time of disposal. We also showed that the local waste management system could influence the distribution of ENMs and give rise to different hotspots of release for ENMs during waste treatment. Future research should focus on the recycling and landfilling of nano-enabled products, since these categories are important for EOL nanoproducts. While so doing, it should be borne in mind that recycling may not be the final destination for EOL products.

\section{Acknowledgements}

The research leading to these results has received funding from the European Union's Seventh Framework Programme under EC-GA No. 604305 SUN. The authors would like to acknowledge Pro-proofreading for helping with the language in this article, Pau Besora for assisting in the maintenance and updating of www.nanodb.dk and Torben Dolin for graphical assistance. 


\section{References}

Andersen L, Christensen F M, Nielsen J M (2014) Nanomaterials in waste: Issues and new knowledge. The Danish Environmental Protection Agency, Project no. 1608, 2014, ISBN no. 978-87-93283-10-7

Asmatulu E, Twomey J, Overcash M (2012) Life cycle and nano-products: end-of-life assessment. J Nanopart Res 14:720.

Boldrin A, Hansen SF, Baun A, Hartmann NIB, Astrup TF (2014) Environmental exposure framework for nanoparticles in solid waste. J Nanopart Res 16:2394.

Bolyard SC, Reinhart DR, Santra S (2013) Behavior of Engineered Nanoparticles in Landfill Leachate. Environ. Sci. Technol. 2013, 47 (15):8114-8122

Caballero-Guzman A, Sun T, Nowack B (2015) Flows of engineered nanomaterials through the recycling process in Switzerland. Waste Management 36:33-43.

European Commission (2012) Commission staff working paper - Types and uses of nanomaterials, including safety aspects. Final version: 3/10-2012. Available online, last accessed 22/1-2016:

http://eur-lex.europa.eu/LexUriServ/LexUriServ.do?uri=SWD:2012:0288:FIN:EN:PDF

Eurostat. Available online, last accessed 22/1-2016: http://ec.europa.eu/eurostat/web/waste

Eymery F, Niaudet A, Cadane A, Merckel O \& Thieriet N (2013) Éléments issus des déclarations des substances à l'état nanoparticulaire. Available online, last accessed 29/3-2016:

http://www.developpement-durable.gouv.fr/IMG/Rapport_public_format_final_20131125.pdf

Gottschalk F, Sonderer T, Scholz RW \& Nowack B (2009) Modeled Environmental Concentrations of Engineered Nanomaterials (TiO2, $\mathrm{ZnO}, \mathrm{Ag}, \mathrm{CNT}$, Fullerenes) for Different Regions. Environ Sci Technol 43:9216-9222.

Hansen SF, Heggelund LR, Besora PR, Mackevica A, Boldrin A, Baun A (2016) Nanoproducts - What is Actually Available to European Consumers? Environ Sci: Nano, advance article (published online 17 December 2015)

Hischier R, Nowack B, Gottschalk F, Hincapie I, Steinfeldt M, Som Claudia (2015) Life cycle assessment of façade coating systems containing manufactured nanomaterials. J Nanopart Res 17:68.

Keller AA, McFerran S, Lazareva A, Suh S (2013) Global life-cycle emissions of engineered nanomaterials. J Nanopart Res 15:1692

Keller AA, Vosti W, Wang $\mathrm{H}$, Lazareva A (2014) Release of engineered nanomaterials from personal care products throughout their life cycle. J Nanopart Res 16:2489.

Keller AA \& Lazareva A (2014) Predicted Releases of Engineered Nanomaterials: From Global to Regional to Local. Environ Sci Technol Lett 1:65-70.

Köhler AR, Som C, Helland A \& Gottschalk F (2008): Studying the potential release of carbon nanotubes throughout the application life cycle. J Cleaner Prod 16:927-937. 
Nanodb.dk, available online, last accessed 8/4-2016: www.nanodb.dk

Nowack B, Ranville JF, Diamond S, Gallego-Urrea JA, Metcalfe C, Rose J, Horne N, Koelmans AA, Klaine SJ (2012) Potential scenarios for nanomaterial release and subsequent alteration in the environment. Environ Toxicol Chem 31, 1: 50-59.

OECD (2016) Nanomaterials in Waste Streams: Current Knowledge on Risks and Impacts. OECD Publishing, Paris. Available online, last accessed 23/5-2016: http://www.oecdilibrary.org/environment/nanomaterials-in-waste-streams_9789264249752-en

Pourzahedi L \& Eckelman MJ (2015) Environmental Life Cycle Assessment of Nanosilver-Enabled Bandages. Environ Sci Technol 49:361-368.

Struwe J \& Schindler E (2012) Bedeutung von Nanomaterialien beim Recycling von Abfällen. Hans Böckler Stiftung Arbeitspapier AP 270.

Sun TY, Gottschalk F, Hungerbühler K, Nowack B (2014) Comprehensive probabilistic modelling of environmental emissions of engineered nanomaterials. Envir Poll 185:69-76.

Walser T \& Gottschalk F (2014) Stochastic fate analysis of engineered nanoparticles in incineration plants. J cleaner prod 80:241-251. 